\title{
Cuando la frontera dialoga: Singularidades de la relación argentino-chilena en las últimas décadas
}

\section{When the border talks: Singularities of the Argentine- Chilean relationship in recent decades}

Miryam Colacrai* (iD) (http://orcid.org/0000-0002-2739-0534)
Recibido el 19 de mayo de 2015. Aceptado el 28 de abril de 2016.

*Autor para correspondencia: Miryam Colacrai, correo electrónico: miryam.colacrai@fcpolit.unr.edu.ar

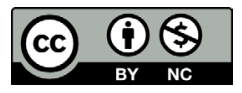

Todos los contenidos de Estudios Fronterizos se publican bajo la licencia Creative Commons Atribución no comercial 2.5 México, y pueden ser usados gratuitamente para fines no comerciales, dando el crédito a los autores y a la revista Estudios Fronterizos.

\footnotetext{
${ }^{1}$ Consejo Nacional de Investigaciones Científicas y Técnicas (Conicet), Buenos Aires, Argentina, correo electrónico: miryam.colacrai@fcpolit.unr.edu.ar
}

\section{Resumen}

El trabajo aborda las relaciones bilaterales entre la Argentina y Chile en las últimas décadas resaltando el potencial de sus nuevas relaciones fronterizas. Sostiene que el amplio abanico de agentes gubernamentales, entidades políticas subestatales y locales y los diferentes canales de vinculación transgubernamental, han dotado a dicha frontera de una dinámica singular, connotándola como espacio de cooperación. El artículo es descriptivo-reflexivo y se organiza alrededor de una serie de preguntas acerca de la búsqueda sostenida de integración fronteriza argentino-chilena desde los años noventa y la construcción de una singular institucionalidad top-down y bottom-up. De la variedad de vínculos existentes, selecciona algunos ejemplos significativos como los Comités de Integración, la conformación de la Zona de Integración Centro-Oeste de América del Sur (Zicosur) y la cooperación argentino-chilena en la Antártida. Asimismo, subraya el contenido integracionista del Tratado de Maipú (2009) y la institucionalidad que cobran las diferentes instancias de diálogo bilateral.

Palabras clave: relación bilateral argentino-chilena, nueva visión de fronteras, relaciones transfronterizas, Comités de Integración, Zicosur, cooperación antártica.

\section{Abstract}

The paper deals with bilateral relations between Argentina and Chile in recent decades, highlighting the potential of their new border relations. It assumes that the wide range of governmental actors, subnational and local entities linking each other have given this a unique dynamic border and are considered spaces of cooperation. The article is descriptive-reflective and is organized around a series of questions about the continued search for Argentine-Chilean border

CÓMO CITAR: Colacrai, M. (2016). Cuando la frontera dialoga: Singularidades de la relación argentino-chilena en las últimas décadas [When the border talks: Singularities of the Argentine-Chilean relationship in recent decades]. Estudios Fronterizos, 17(34), 85-99, https://doi.org/10.21670/ref.2016.34.a05 
integration since the nineties and the construction of top-down and bottom-up institutional agreements. Within the variety of links, some remarkable examples are selected for the article like the "Integration Committees", the settlement of the Central West of South America Integration Zone (Zicosur) and the Argentine-Chilean cooperation in Antarctica. It stresses the integrationist Maipú Treaty (2009) and institutions that charge different instances of bilateral dialogue.

Keywords: Argentine-Chilean bilateral relationship, new vision of borders, trans-border relations, Integration Committees, Zicosur, Antarctic cooperation.

\section{Introducción}

Durante la década del setenta y una parte de los ochenta, el espacio sudamericano se caracterizó por transitar una ola de gobiernos militares (dictatoriales) cuyas acciones de política exterior estuvieron signadas por controversias territoriales, lecturas geopolíticas ortodoxas y muy escaso margen para llevar adelante políticas de concertación e integración. Se asignaba gran prioridad a las cuestiones territoriales con lo cual se estimulaban miradas desconfiadas hacia los vecinos y se pensaba en "juegos de suma cero" en lo relativo a la problemática limítrofe.

Las relaciones entre la Argentina y Chile en aquella época no escaparon a estas características generales. Por el contrario expresaron, en buena medida, este "reduccionismo conceptual" y tensaron la cuestión al punto de llegar casi a un enfrentamiento armado en las navidades de 1978.

Algunos años después y como resultado de un proceso arduo de negociación donde la mediación papal ocupó un rol determinante, se dio un primer paso significativo en la relación: el Tratado de Paz y Amistad de 1984. Este instrumento jurídico fue muy claro al señalar la obligación de solucionar siempre todas las controversias en forma pacífica y de no recurrir jamás a la amenaza o al uso de la fuerza en sus relaciones mutuas.

En la década de los noventa, comenzó a construirse progresivamente una nueva relación político-estratégica, asumiéndose el compromiso de arribar a la solución del conjunto de contenciosos vinculados al eje soberano territorial. De ese modo, la percepción de amenazas de carácter vecinal, disminuyó hasta prácticamente hacerse nula. El discurso de ambos países fue mutando hacia una nueva configuración de ideas y expresiones acerca del otro, con lo cual se fue desdibujando aquella visión preexistente de virtual amenaza.

Paulatinamente el trabajo negociador expresado en reuniones entre Cancillerías y Ministerios de Defensa y el diseño de algunas políticas consistentes con el avance de las Medidas de Confianza Mutua (Мсм), pavimentó el camino hacia un alto grado de transparencia, como por ejemplo la producción y publicación de libros de defensa nacionales donde - ya con nuevas miradas- se definían los ámbitos de acción y las principales orientaciones de la política de defensa y del uso de la fuerza. Por su parte, la formalización y la ejecución sistemática de medidas de confianza mutua de carácter militar, propiciaron un mayor nivel de conocimiento y generaron mejores condiciones para el desarrollo de la confianza.

En esa línea, este trabajo hipotetiza acerca del diseño de un patrón de vínculos progresivo y constructivo, en un marco de relación bilateral democrática sostenida y con tendencia a profundizarse. Dicha relación está anclada en una concepción de frontera que muta desde una concepción donde se priorizaba el "límite y la separación" hacia otra 
que adquiere un carácter cooperativo e integracionista en la cual, además de la voluntad política puesta de manifiesto por las autoridades estatales se suman los contactos a escala subnacional, otorgándole gran singularidad y dinamismo.

Ciertas preguntas claves pueden dar sentido a la indagación realizada, a saber: 1) ¿qué procesos ponen en evidencia la búsqueda sostenida de integración fronteriza argentinochilena?; 2) ¿cómo se organiza institucionalmente esa dinámica combinando acciones topdown y bottom up?; 3) ¿en qué medida la voluntad política estatal de Argentina y de Chile ha avanzado en la cooperación en áreas estratégicas — como es el caso de la Antártidaimpensable desde una mirada geopolítica decimonónica que impulsaba la separación y no la cooperación?

Sobre la base de estas consideraciones marco, este trabajo ${ }^{2}$ persigue los siguientes propósitos: en primer lugar, recorrer someramente definiciones de "frontera" para arribar a la que consideramos operativa para el caso que nos ocupa. Seguidamente desarrollar algunos ejemplos puntuales de relaciones de cooperación subnacional y transgubernamental que se han dado entre la Argentina y Chile en los últimos decenios para desembocar en un análisis reflexivo del Tratado de Maipú (2009), donde se dan pasos institucionales tendientes a la profundización de la misma. Asimismo, destacaremos algunos hitos relevantes de la cooperación antártica entendiendo que allí también se expresa una nueva mirada de la frontera y, finalmente, culminaremos el trabajo con algunas reflexiones y conclusiones.

\section{La concepción de frontera. De las definiciones canónicas a las emergentes en base a una perspectiva constructivista}

La Ciencia Política, el Derecho Internacional y las Relaciones Internacionales han coincidido en sus definiciones acerca del Estado y sus funciones. En sus versiones clásicas entienden que el Estado cumple su actividad específica en un espacio territorial determinado, el cual constituye la base espacial de su sistema jurídico y de su soberanía. En consistencia con dicho concepto, la concepción jurídica de frontera remite al principio de jurisdicción territorial, lo que la diferencia radicalmente de definiciones que ofrecen otras disciplinas y campos de estudio. La función de la frontera es, dicho de modo genérico, determinar los espacios que constituyen el territorio de un Estado —sometido a su jurisdicción- con relación al territorio de otro Estado.

Somos concientes de la necesidad de aggiornar el concepto tradicional de frontera a partir de visiones que ponen el énfasis en la interdependencia y la cooperación trasfronteriza, distanciándonos de aquellas perspectivas que cuestionan fuertemente la figura del Estado y anuncian un mundo sin fronteras (Ohmae, 2008).

De modo creciente tiende a afirmarse que las fronteras han dejado de ser líneas divisorias que separan países, como lo han sostenido diversos especialistas. Sin perjuicio

\footnotetext{
${ }^{2}$ El presente texto refleja una selección de cuestiones y es solo parte de una línea de investigación que se viene desarrollando desde 2006, en la cual se presta atención al entramado de relaciones entre regiones y subdivisiones gubernamentales. Ellas forman parte de las relaciones "transgubernamentales" que tienen que ver tanto con divisiones territoriales (provincias, regiones, gobiernos locales) como con áreas funcionales (carteras ministeriales, parlamentos, universidades, áreas de Ciencia y Tecnología, etc.). Los procesos abordados constituyen la preocupación central de proyectos de investigación del Consejo Nacional de Investigaciones Científicas y Técnicas (Conicet) y del Proyecto en curso correspondiente al Programa de Incentivos bajo el Código19/C265 (Argentina).
} 
de la varidad de trabajos sobre cuestiones fronterizas, resultan interesantes e innovadoras las aportaciones de Eusebio Medina (2006) quien propone una epistemología para los estudios de fronteras internacionales, haciendo foco en la necesidad de acometer los estudios sobre fronteras desde una perspectiva interdisciplinar y transfronteriza que supere las limitaciones de los tradicionales enfoques historicistas y geopolíticos. Por su parte, Nicole Diesbach (2002), discute la necesidad de apuntar a un nuevo paradigma dado que, usualmente, el término frontera - con nuestro cuadro mental tradicional basado en la fragmentación - insinúa separación, demarcación o hasta obstáculo; pocas veces, encuentro, reunión, enriquecimiento mutuo y aún amistad. Se ha gestado así un escenario donde se tejen todo tipo de relaciones sociales, económicas, políticas, culturales, medioambientales, a través de variados mecanismos y canales de vinculación que exhiben diferentes grados de institucionalización. Para el caso que analizamos, encontramos coincidencias con Boisier (2003, p. 31) cuando destaca la importancia de regiones fronterizas, definiéndolas como espacios subnacionales limítrofes a países vecinos, en los cuales se manifiestan formas particulares de relaciones y superposición de dos o más estilos económicos y de dos (o más) modelos diferentes de política económica.

Asimismo, vale recordar a Schmitter (1989, p. 120) en sus referencias a los procesos de reintegración en América Latina sostenidos a partir de la vuelta a la democracia de la región en la década de los ochenta. Señala que mientras sea mayor la participación de la comunidad interesada en intervenir en actividades propias de la integración, actuando libremente con el apoyo de la autoridad, mayor será la posibilidad de reciprocidad entre los interesados y más fácil será la búsqueda de acuerdo entre las partes, logrando mejores condiciones para una respuesta asociativa. Es decir, la democracia proveerá espacios a diversos actores en las mesas de negociación donde puedan ser manifestados sus intereses. A ello podríamos agregar que, los mismos actores harán sus propuestas de asociatividad desde abajo (bottom up).

Una combinación de elementos objetivos — como los mencionados arriba- con cuestiones simbólicas que tienen que ver los cambios que se producen en la "mirada del otro" desde cada lado de la frontera, sumado a la convicción sobre la necesidad de concertar para poder enfrentar desafíos comunes, constituirían los signos salientes del nuevo modo de concebir las fronteras. Es por ello que consideramos relevante adoptar la visión "constructivista" de Alexander Wendt (1992) al definir las relaciones internacionales como una construcción social y la "anarquía" —es decir la falta de gobierno de carácter global- como un producto de la interrelación de las partes: "la anarquía es lo que los Estados hacen de ella". ${ }^{3}$ De tal modo, parafraseamos al autor diciendo: "la frontera es lo que los Estados hacen de ella”. No hay un único modo de concebir la frontera. Según momentos históricos y anclajes políticos — cómo el estado se percibe a sí mismo y al otro— las fronteras podrán funcionar para separar o para unir y favorecer el trabajo conjunto y la participación de los diversos actores subnacionales que se hallan comprometidos, haciendo que también se vayan moldeando sus intereses.

Este amplio abanico de agentes gubernamentales, entidades políticas subestatales y locales y los diferentes espacios de vinculación transgubernamental, se han vuelto

\footnotetext{
${ }^{3}$ Para los teóricos constructivistas, las relaciones internacionales son una realidad social, compuesta por hechos sociales que dependen de un acuerdo social y que, por tanto, se dan por hecho; en consecuencia, las relaciones internacionales existirán en la medida en que el acuerdo exista, configurando de esta manera la forma en que categorizamos el mundo y lo que hacemos. Una pregunta fundamental con la que se toma distancia de las teorías predominantes, es si la "anarquía" realmente existe o si es producto de ciertas prácticas sociales en un contexto histórico determinado (Wendt, 1992). Asimismo plantea la relación agenteestructura como mutuamente constitutiva.
} 
particularmente relevantes a la hora de estudiar las relaciones bilaterales entre Argentina y Chile y han dotado a la frontera de una dinámica singular.

La densidad de estas relaciones bilaterales resulta inabarcable en el espacio de un artículo, por lo cual hemos seleccionado algunos ejemplos que nos permiten visualizar que esa concepción constructivista de frontera es la que mejor representa la dinámica actual. ${ }^{4}$ La selección muestra, en primer lugar, los "Comités de Integración" que combinan acciones top-down/bottom up, es decir, decisiones desde la esfera gubernamental nacional con propuestas provenientes de la escala subnacional. Seguidamente, dedica atención a un complejo proceso, hoy convertido en una macroregión como es la Zona de Integración Centro-Oeste de América del Sur (Zicosur), con orígenes en iniciativas empresariales que datan de la década de los setenta y posee una impronta marcadamente subnacional (bottom up), con una agenda que excede cuestiones económico-comerciales e incursiona con fuerza en aspectos culturales. Finalmente, se da cuenta de un caso paradigmático de "construcción de la confianza y cooperación" en el ámbito antártico que, visualizado como parte de la agenda de la "alta política" e integrante de una "frontera no definida" entre la Argentina y Chile, demoró en convertirse en un espacio de negociación y trabajo conjunto.

\section{Los contactos y vínculos a escala subnacional expresados en la dinámica de los "Comités de Integración"}

El conjunto de relaciones argentino-chilenas, que resultan vitales a la hora de comprender el afianzamiento de esta relación bilateral, incluye a los denominados actores subnacionales o gobiernos no centrales, esto es, las provincias argentinas y las regiones chilenas, como así también los municipios, que en su accionar y en el modo de vincularse van generando una especie de estado red.

El interés puesto en la priorización de pasos y corredores bioceánicos, la comunicación transfronteriza, la realización de obras viales, la reactivación o trazado de nuevas líneas de ferrocarriles y una variada agenda de cuestiones afines al turismo, al empleo de recursos compartidos y a temas ambientales pertenecen al amplio abanico de issue areas que tienen a dichos actores como principales protagonistas.

Aquella visión de favorecer el intercambio y la idea de "vecindad" que quedó plasmada tímidamente en el acuerdo de 1984 (Tratado de Paz y Amistad de 1984), se concretó con una primera experiencia: el Comité de Frontera para el Paso Internacional Sistema Cristo Redentor, creado mediante el Acta de la Comisión Binacional Argentino-Chilena de Cooperación Económica e Integración Física en abril de 1987. Desde entonces el número de dichos comités - hoy llamados de Comités de Integración- creció hasta los ocho con que cuenta actualmente. ${ }^{5}$ Es importante aclarar que, a diferencia de lo que ocurre con otros países de América del Sur, donde muchas veces la "frontera" entre dos países pasa casi inadvertida porque no existe un accidente geográfico que los separe (en algún caso la separación entre dos países es simplemente una avenida en un centro urbano) en el caso

\footnotetext{
${ }^{4}$ Téngase en cuenta que, entre los vínculos pactados entre la Argentina y Chile, se reconocen más de 45 mecanismos.

${ }^{5}$ Los existentes hasta el momento, con la incorporación del Comité Las Leñas en 2011 son ocho, NOA-Norte Grande; Atacalar (Atacama-Catamarca-La Rioja); Agua Negra; Sistema Cristo Redentor, Pehuenche; Región de Los Lagos; Integración Austral.
} 
que nos ocupa, se tiene la barrera de la Cordillera de los Andes. Por ello, el trabajo relativo a los pasos de frontera y su agilización se ha convertido en una prioridad. De los 75 pasos fronterizos con los que cuenta Chile, no todos se encuentran en funcionamiento, por lo cual, desde provincias, regiones y localidades se solicita permanentemente prestarles la debida atención para hacerlos operativos.

En sus inicios, los Comités de Frontera eran grupos de trabajo reunidos con el propósito de facilitar el tránsito transfronterizo, luego incorporaron más actividades para atender aspectos de desarrollo local, salud, infraestructura y otras cuestiones que fueran relevantes para el mejoramiento de las regiones limítrofes.

La evolución que tuvo la interdependencia transfronteriza y la necesidad de dotarla de un marco institucional para la negociación, a la vez que se producía un cambio de mirada de su funcionalidad, hizo que ellos pasaran a llamarse Comités de Integración. Al respecto, resulta interesante reproducir parte de las consideraciones que se hacen en el Decreto 278, el cual recoge el intercambio de notas producido por el embajador argentino Carlos Abihaggle y el subsecretario de Relaciones Exteriores de Chile, Alberto Van Klaveren Stork. En dichas notas se hace referencia a las "iniciativas de cooperación de las regiones chilenas y las provincias argentinas", a la consideración de dichos comités como "foros privilegiados" y la "voluntad de consagrar su interés común", entre sus fundamentos.

Su rol ha sido crucial y su magnitud queda a la vista con la sola mención de que la frontera argentino-chilena es la segunda en extensión en el mundo. La frecuencia de las reuniones es anual y se hacen en uno u otro país, de manera alternada.

En 1997, se les dotó de una regulación institucional con base en un acuerdo entre los dos países, que faculta a la creación de comisiones en su interior para abordar temas específicos, estableciendo que las recomendaciones adoptadas en las reuniones de los comités sean elevadas a las respectivas cancillerías para su evaluación y decisión. Su propio desarrollo llevó a que, dentro del marco de sus reuniones, comenzaran a realizarse Encuentros de Alcaldes e Intendentes de ciudades que forman parte de las regiones y provincias involucradas.

Podría afirmarse que también han ampliado su radio de acción ya que este espacio de contactos que ofrecen los Comités de Integración mereció el reconocimiento no solo de las provincias fronterizas sino que, además, ha concitado el interés de participar por parte de otras provincias que se beneficiarían, sobre todo con la construcción de obras de infraestructura en las áreas de pasos fronterizos. ${ }^{6}$

El Tratado de Maipú de Integración y Cooperación entre la República de Chile y la República de Argentina, firmado por las presidentas Cristina Fernández de Kirchner y Michelle Bachelet el 30 de octubre de $2009,{ }^{7}$ hace un reconocimiento muy significativo de la actividad de los Comités de Integración y en general de la actividad subnacional, en términos de su contribución positiva al fortalecimiento y profundización de las relaciones bilaterales. Este acuerdo representa, por un lado, el reconocimiento de los avances logrados en más de 25 años contados desde el primer Tratado de Paz y Amistad firmado por el presidente Alfonsín en 1984 y, por otro, la fijación de metas o una "hoja de ruta" hacia una integración más completa y profunda.

\footnotetext{
${ }^{6}$ Tal es el caso del Túnel Agua Negra (provincia de San Juan-IV Región) que resultaría muy útil para la comunicación hacia el Pacífico de las provincias de la Región Centro (Santa Fe, Córdoba y Entre Ríos); de allí que gestionen su participación en las discusiones aunque geográficamente no pertenecen a la frontera andina. Asimismo, la provincia de Santa Fe se ha incorporado a Atacalar.

${ }^{7}$ De acuerdo con el Boletín Oficial de la República Argentina, se convirtió en Ley 26561, sancionada el 18 de noviembre de 2009 y promulgada el 17 de diciembre de 2009. Ratificado por ambos congresos (Argentina y Chile) en noviembre, entró en vigencia el 22 de enero de 2010.
} 
En su articulado, se destina una atención importante —entre los artículos 15 al 21 inclusive- a los Comités de Integración, consignándose su rol, sus objetivos y la especificidad de sus funciones. La definición que allí se presenta es la más apropiada para describir las funciones que ellos cumplen, entendidos como "foros de encuentro y colaboración entre los sectores público y privado nacionales y de las Regiones chilenas y Provincias argentinas para promover su integración, con el apoyo de los organismos nacionales, provinciales, regionales y municipales" (Tratado de Maipú, 2009, p. 5). Se preveía también la necesidad de proceder a una reforma del Reglamento para los Comités de Integración de funcionamiento vigente (Acuerdo entre la República de Chile y la República de Argentina, 2011).

La puesta en marcha, el 22 de enero de 2010 del Tratado de Maipú (2009), ha permitido la institucionalización de diversos mecanismos preexistentes, erigiéndose como hoja de ruta para la promoción y desarrollo de las relaciones bilaterales en una variedad de niveles ${ }^{8}$ y ha producido algunos avances concretos en las reuniones de gobernadores y autoridades regionales, así como también en las reuniones de la Comisión Parlamentaria Conjunta. Por tanto, las reuniones de parlamentarios en la Comisión Conjunta y la ahora institucionalizada reunión de gobernadores de manera periódica, como parte de la "relación institucionalizada", debe ser valorada y reconocida como una de las innovaciones para toda la política exterior de la Argentina y de Chile porque están acercando las decisiones a los ciudadanos.

La experiencia de los Comités de Frontera es exitosa, pero no la única. Las provinciasy regiones han emergido como actores importantes en la relación bilateral de la mano de una diversidad de acuerdos, visitas y proyectos que es importante tomar en consideración. Del lado argentino, algunas provincias han sabido hacer una interesante tarea de influencia y cabildeo, para que sus intereses sean tomados en cuenta por el gobierno central, como veremos a continuación.

Un ejemplo superlativo del accionar de provincias argentinas es el que muestran Mendoza y San Juan con su ejercicio constante de "cabildeo", para atraer la atención y el compromiso del estado nacional para la realización de obras de infraestructura y conectividad vial en el área fronteriza con Chile. De hecho, además de ser las provincias que tradicionalmente y por diversas razones, siempre estuvieron más cercanas a Chile, su ubicación estratégica en el centro neurálgico de las vías transfronterizas constituye una potencialidad convenientemente remarcada por las autoridades provinciales. Además han hecho hincapié en que la "conectividad" que desde ellas se pueda construir tendría no solo impacto binacional, sino que ofrecería beneficios para los espacios más amplios de los corredores bioceánicos mercosureños.

Además de las reuniones en los Comités de Integración, estas provincias pudieron acceder a diversas Comisiones Mixtas Binacionales, produciéndose el hecho más

\footnotetext{
${ }^{8}$ Se establece en su artículo 3 que:

...las Partes dispondrán de los siguientes mecanismos bilaterales: Encuentros presidenciales, Reunión Binacional de Ministros, Sistema de Consultas Permanentes de los Ministerios de Relaciones Exteriores, Comisión Binacional de Cooperación Económica e Integración Física, Comisión Binacional de Comercio, Inversiones y Relaciones Económicas, Comisión Parlamentaria Conjunta y Comités de Integración.

Una buena parte de estos mecanismos registran actividad anterior al Tratado, pero lo relevante aquí es que se los reconoce como "parte constitutiva de la institucionalidad" con la que cuenta esta relación bilateral (Colacrai, 2010, p. 350). Asimismo, de la lectura del Tratado completo se infiere que alrededor de $60 \%$ de su articulado se refiere, de una u otra manera, a las relaciones del tipo transgubernamental y subnacional (actores gubernamentales provinciales y locales).
} 
significativo al haber logrado que el Tratado de Maipú incluyera dos protocolos complementarios. Uno de ellos es el Protocolo Complementario sobre la Constitución de la Entidad Binacional para el Proyecto del Túnel de Baja Altura-Ferrocarril Trasandino Central, ${ }^{9}$ el otro relativo al Protocolo Complementario sobre la Constitución de la Entidad Binacional para el Proyecto Túnel Internacional Paso de Agua Negra. ${ }^{10}$ Con la firma de estos instrumentos por parte de los gobiernos de Argentina y Chile, las provincias mencionadas se han asegurado un asiento en el seno de las respectivas comisiones binacionales.

Los avances en pro de la conectividad no son todo lo ágiles que las provincias y regiones esperan, se ha tratado hasta el momento de coordinar legislación hacia ambos lados de la Cordillera, realizar importantes estudios de impacto ambiental y la posibilidad de combinar esfuerzos financieros públicos y privados para obras de esta envergadura.

Este camino recorrido, alienta a otras provincias y regiones - por ejemplo las patagónicas- para que sus pasos fronterizos sean priorizados y se abran, de ese modo, nuevas posibilidades de conectividad e intercambio.

Como hemos explicitado en este apartado, el entramado de vínculos que se ha producido involucra decisiones gubernamentales a escala central que estimulan y acompañan las propuestas provenientes del nivel subnacional.

En suma, los procesos que aquí hemos relevado, en su trayectoria y progresión exhiben las tres condiciones fundamentales que Rhi y Conato (2009) señalan como favorecedoras de la cooperación fronteriza, a saber: que los territorios comprendidos participen en un proceso de conectividad física; que se cuente con una voluntad y un acuerdo político de alto nivel entre los países involucrados que permita materializarse en algún marco institucional de ordenación de sus relaciones y, por último, que se reconozca la participación de los gobiernos subnacionales fronterizos, en cuanto articuladores de los actores locales, como instancia institucional fundamental para una positiva gobernanza transfronteriza.

\section{La conformación de regiones transfronterizas de carácter multiestatal y dimensión subnacional. El caso de Zicosur}

Como parte del crecimiento progresivo de vínculos de carácter subnacional, es decir, llevados adelante por gobiernos no centrales - locales, provinciales o regionales- se han multiplicado las instancias de cooperación e integración en términos de comercio, cultura, turismo, etc. Se ha producido una dinámica donde se priorizan aspectos relativos a esa "integración cercana o más próxima" comparada con los grandes procesos de integración regional en los cuales se la percibe, muchas veces, desplazada o marginada.

El ejemplo más claro estaría representado, a nuestro criterio, por la Zona de Integración Centro-Oeste de América del Sur, conocida bajo la sigla Zicosur, a la que se

\footnotetext{
${ }^{9}$ En el caso de la conectividad a la altura del Cristo Redentor, uno de los primeros antecedentes fue el proyecto de rehabilitación del ferrocarril trasandino propuesto por la empresa mendocina Tecnicagua en el 2007. En 2008, se sumaron otras iniciativas privadas que, en marzo de 2009 , elaboraron el primer estudio de factibilidad. En octubre del mismo año, las presidentas de Chile, Michelle Bachelet, y de la Argentina, Cristina Fernández, constituyeron en Maipú la Entidad Binacional encargada de conducir desde los respectivos Estados la implementación del proyecto.

${ }^{10}$ Acorde con declaraciones recientes del embajador de Chile en Argentina, Marcelo Díaz Díaz, toma fuerza el anuncio de que en 2015 se licitará definitivamente el Túnel de Agua Negra (Aseguran que la Relación entre Argentina y Chile, 2015).
} 
podría caracterizar como una región transfronteriza de carácter multiestatal y dimensión subnacional. Esta particular institución —considerando institución en sentido ampliosurgió "oficialmente" en una reunión celebrada en Antofagasta en $1997^{11}$ y reúne regiones argentinas, chilenas, bolivianas y paraguayas. Son miembros de esta instancia las siguientes regiones: de la Argentina, las provincias de Catamarca, Chaco, Corrientes, Formosa, Jujuy, Misiones, Salta, Santiago del Estero y Tucumán; de Bolivia, los departamentos de Beni, Chuquisaca, Cochabamba, Oruro, Pando, Potosí, Santa Cruz y Tarija; de Brasil, el estado de Mato Grosso del Sur; de Paraguay, las regiones de Alto Paraguay, Alto Paraná, Amambay, Boquerón, Caaguazú, Caazapá, Canindeyú, Central, Concepción, Cordillera, Guairá, Itapuá, Misiones, Neembucú, Paraguarí, Presidente Hayes y San Pedro; de Chile, las regiones de Arica y Parinacota, Atacama y Tarapacá y de Perú, los departamentos de Arequipa, Moquegua y Tacna. Este espacio reúne a una población cercana a los 40 millones de habitantes, en una superficie de $4200000 \mathrm{~km}^{2}$ (si comparamos con el total de la población de la Argentina, el dato no es menor).

Entre sus funciones principales encontramos la de posibilitar la discusión y diseño de políticas desde la conjunción de lo público y privado, proyectar una oferta exportable común competitiva, basada en las ventajas que ofrece del lado chileno por la infraestructura portuaria existente para acceder a los mercados demandantes de la producción común, especialmente los del Asia Pacífico.

Precisamente, una de sus consignas más fuertes es la de trabajar sobre la infraestructura vial, ferroviaria e hidrovial y sobre la facilitación de los trámites en los puntos fronterizos de los cinco países (Argentina, Chile, Bolivia, Brasil y Paraguay).

En 2011, se produjo un hecho inédito en la Cancillería argentina cuando hubo una presentación oficial de la Zicosur para darle visibilidad nacional e internacional. También en esa sede, el 20 de noviembre de 2013 tuvo lugar con gran acogida el Primer Seminario Zicosur Integra, el cual puede considerarse colofón de una serie de actividades previas importantes. ${ }^{12}$

Si se analiza la evolución de todo el proceso Zicosur, es notoria la similitud y emulación de mecanismos ya existentes en el Mercado Común del Sur (Mercosur) y ciertos pasos dados con vistas a su institucionalización. También se destaca porque avanza en actividades que trascienden los intereses económicos, de infraestructura y planeamiento regional para comprometerse, progresivamente, en emprendimientos institucionales, culturales y de coordinación interuniversitaria, como ha quedado de manifiesto en la reunión de fines del año 2007, en la cual se presentó el Programa de Movilidad Estudiantil (PME) de la Red Criscos, dependiente del Consejo de Rectores por la Integración de la Subregión Centro Oeste de Sudamérica (Hoy Finaliza en la UNCa, 2007).

La Red se formó en 1996 en la ciudad de Antofagasta luego de tres reuniones preliminares de rectores de universidades de la sub-región. La primera ocurrió

\footnotetext{
${ }_{11}$ Podría citarse a este proceso integrativo de carácter subnacional, como el primero de estas características, surgido como Foro Empresarial que data de 1977 cuando el Grupo empresario Interregional del Centro Oeste Sudamericano (GEICOS) inicia las primeras reuniones empresariales de la región. Luego, se sumaron diferentes actividades, promoción de productos, realización de ferias y contactos entre gobernadores.

12 En virtud de un acuerdo con el Consejo Federal de Inversiones, firmado el 28 de octubre de 2011, el CFI ha financiado la participación del Ente Zicosur en diversos eventos durante el año 2012, a saber: Participación y financiación de estands de la entidad Zicosur en la Feria del Libro 2012 (Buenos Aires), en Ferinoa, en la Fiesta Nacional del Algodón y en la Exposición Industrial de Matto Grosso, Brasil. Expocruz 2012 (21 al 30 de septiembre de 2012 en Santa Cruz de la Sierra, Bolivia), en el World Food Moscu (17 al 20 de septiembre del 2009), participación y financiamiento de estand y en la World Association of Investment Promotion Agencies, en Dubai (participación de la presidencia Pro Tempore el día 18 de septiembre del 2012).
} 
en 1993 en la ciudad del Salta, en Argentina y el mismo año, en la ciudad de Iquique, en Chile. Finalmente, al año siguiente, se suscribe, en Argentina, el Convenio de Cooperación entre las Universidades de la Subregión Centro Oeste de Sudamérica que posteriormente se convertiría en CRIScOs... Reúne en total a 25 universidades de la región (7 universidades peruanas, 4 en el norte de Chile -de la I a la IV región-, 9 del norte de Argentina -Jujuy, Salta, Santiago del Estero, Tucumán, Catamarca y La Rioja - 4 de Bolivia y 1 de Paraguay), (ANR International, 2013, párr. 2-3).

Es decir, nos encontramos frente a un fenómeno —también novedoso a nivel regional- que promueve la Cooperación en Educación Superior en un área de confluencia subnacional.

Criscos desarrolla, desde sus inicios, el PME, cuyo objetivo es establecer y estrechar vínculos de colaboración para la integración subregional, mejorar la calidad de los servicios educativos de las universidades miembros y favorecer las relaciones con organismos e instituciones internacionales de la red. ${ }^{13}$ Desde que se puso en marcha este programa, son 1693 los universitarios que han podido viajar a una de las cinco naciones participantes de este modelo educativo (Universidad Arturo Prat, s. f.).

Como lo demuestran las redes de intercambio académico existentes en diversos espacios regionales y desde esas regiones hacia el exterior —estimulando diálogos académicos interregionales- a todas ellas las mueve el propósito de generar nuevas miradas respecto "del otro", a través del conocimiento y el desarrollo de actividades compartidas que socializan a sus integrantes. Sin duda, también desde aquí es posible ir construyendo nuevas imágenes y significados intersubjetivos, tal como indica una de las innovaciones que ofrece el constructivismo para el estudio de las Relaciones Internacionales.

\section{Avances en temas relativos a la Antártida: Una "frontera poco común" entre la Argentina y Chile}

Los temas antárticos siempre han ocupado un lugar de relevancia en las relaciones bilaterales entre la Argentina y Chile y, en buena medida, han reflejado las percepciones de diferentes momentos políticos en ambos países.

De modo muy breve, recordaremos que los primeros acercamientos a nivel interestatal se produjeron a comienzos del siglo XX, en respuesta a los reclamos británicos sobre toda la Antártida, entre 1907 y 1908. Casi al unísono, desde uno y otro lado de la Cordillera se percibió la necesidad de actuar conjuntamente. Es por ello que el Ministro de Relaciones Exteriores argentino, Estanislao Zeballos sostenía en 1907: "Inglaterra reclama todas esas tierras, tendremos que defendernos unidos" (Pinochet de la Barra, p. 6, 1999). Por su parte desde Chile, Puga Borne advertía: "Chile y Argentina deben aunar su acción para hacer valer sus derechos en contra de la pretensión inglesa” (Pinochet de la Barra, p. 6, 1999).

\footnotetext{
${ }^{13}$ Con un movimiento anual de un centenar de alumnos entre las universidades participantes, la red Criscos ofrece posibilidades de estudios en las áreas de Medicina Veterinaria y Zootecnia, Agronomía, Antropología, Educación, Trabajo Social, Administración, Mecánica Eléctrica, entre otras. Además, las universidades se comprometen a cubrir los gastos de hospedaje, alimentación, enseñanza y otros servicios académicos de los becarios Criscos. Este diseño de programas de intercambio y el modo de hacerlos operativos se asemeja al Programa Escala (Mercosur).
} 
Varias décadas después, Argentina y Chile formularon el 12 de julio de 1947 - teniendo como eje la cuestión antártica y su vinculación con la soberanía- la Declaración Conjunta sobre sus derechos en los respectivos sectores y promovieron la idea de concertar oportunamente un tratado con el objeto de demarcar los límites correspondientes. ${ }^{14}$ De ese modo acordaron llevar adelante una política "pragmática", (haciendo una lectura de costo-beneficio) para la determinación de la frontera de ambos Estados en la región antártica. Expresaron allí su deseo de "llegar lo antes posible a la concertación de un tratado argentino-chileno de demarcación de límites en la Antártida Sudamericana" (Declaración Conjunta Argentino-Chilena, p. 2, 1947). Todos ellos no dejaron de conformar meras intenciones, sobre todo porque la superposición de parte de sus reclamos territoriales siempre aparecía como una cuestión oponible a la otra parte, solo minimizada cuando se la confrontaba con las aspiraciones británicas que abarcaban la totalidad de dichos reclamos. Ese tipo de disputas por la soberanía quedaron suspendidas al firmarse el Tratado Antártico en 1959 que comprometió originalmente a sus doce países signatarios aunque en virtud de su artículo iv, han quedado contempladas como aspiraciones territoriales preexistentes a dicho acuerdo.

El periodo comprendido entre las décadas de los setenta y ochenta fue más bien de "competencia y coexistencia distanciada". Los respectivos gobiernos militares tuvieron una visión de la geopolítica reduccionista y confrontativa, y trasladaron a las cuestiones antárticas dicha impronta. Así las políticas implementadas en ambos países como la multiplicación del número de bases instaladas en la Antártida, el desarrollo de políticas de población —favorecer nacimientos en territorio antártico-; la adquisición de buques polares, rompehielos y tecnología antártica que pusieran a cada país en el primer lugar fueron todas acciones que se dieron casi simultáneamente y que alentaban dicha competencia.

Durante la década de los noventa se inicia un ciclo de cooperación antártica que presenta rasgos singulares si se le compara con otros momentos de la relación bilateral. El puntapié inicial de una "renovada" búsqueda de cooperación en la Antártica, se concretó en la Declaración Conjunta sobre la Antártida entre los presidentes Patricio Aylwin Azócar (Chile) y Carlos Menem (Argentina), en la reunión celebrada el 29 de agosto de 1990. Con ella se ratificaron las anteriores Declaraciones Conjuntas (1941- 19471948-1971-1974), se promovieron intercambios y se planteó la posibilidad de llegar a un Programa Argentino-Chileno de Cooperación Científica Antártica. A partir de entonces, las cumbres presidenciales siempre han incluido aspectos antárticos de relevancia, incluso han establecido compromisos ambientales expresos.

Deben destacarse tanto el tratamiento de cuestiones antárticas en el ámbito de la Comisión Parlamentaria Conjunta ${ }^{15}$ como así también, la inclusión de la cooperación antártica como un punto significativo en el Tratado de Maipú (2009) firmado por las entonces Jefas de Estado Cristina Fernández de Kirchner y Michelle Bachelet.

\footnotetext{
${ }^{14}$ Esta declaración es conocida con los nombres de los cancilleres signatarios Bramuglia (Argentina). Juliet Gómez (Chile). Ella recuerda como antecedentes las conversaciones mantenidas en 1941 entre Isidoro Ruiz Moreno (Argentina) y Julio Escudero Guzmán (Chile) donde, reconociendo que ambos países tenían derechos indiscutidos sobre la Antártida, acordaban llevar adelante una política amistosa para la determinación de los mismos. Eso había quedado expresado en el Acta Final de la reunión celebrada en Santiago de Chile el 26 de marzo de 1941.

${ }^{15}$ Recuérdese que en la Primera Sesión Parlamentaria Conjunta, celebrada por diputados argentinos y chilenos en la Base Presidente Eduardo Frei Montalva el 7 de marzo de 2009, en Chile, rechazaron el reclamo inglés de un millón de $\mathrm{km}^{2}$ como su plataforma en áreas antárticas. Asimismo, en la XVII Reunión Plenaria de la Comisión Parlamentaria Conjunta Argentino-Chilena, en Buenos Aires, el 28 de abril de 2011, instaron a los Poderes Ejecutivos para que concreten la instalación de una base científica conjunta en la Antártida.
} 
Como parte de la continuidad de la cooperación antártica argentino-chilena, puede señalarse un avance y profundización de la misma, con la creación del "Comité Ad-hoc Sistema del Tratado Antártico" que consta en la Declaración Presidencial del 16 de marzo de 2012, firmada por la Presidenta Cristina Fernández de Kirchner y el presidente de Chile Sebastián Piñera Echenique. Dicho Comité asume, de ese modo, la tarea de reflexionar y promover posiciones conjuntas en los diferentes foros y regímenes atinentes a la Antártida.

Su tarea, ya desarrollada en dos reuniones sucesivas, ha sido reflexionar y promover posiciones conjuntas en los diferentes foros y regímenes del referido sistema. En cuestiones relativas a los recursos vivos marinos antárticos, ratificaron conjuntamente su total compromiso con la Convención para la Conservación de los Recursos Vivos Marinos Antárticos (CCRVMA) y su firme decisión de enfrentar cualquier "imposición de regulaciones y gravámenes incompatibles con aquella" (Declaración Presidencial Conjunta MenemAylwin, p. 7, 1990). Otra actividad que pone en evidencia la cooperación bilateral es el desarrollo conjunto de la Patrulla Antártica Naval Combinada (PANC), la cual tiene por misión salvaguardar la vida humana en el mar y combatir la contaminación para prevenir emergencias en aguas antárticas; su planificación y trabajo en terreno, implica el trabajo conjunto de las armadas argentina y chilena, entre otras diversas tareas que también se han extendido en el área del Canal Beagle.

Precisamente, debido al aumento del tránsito marítimo del canal Beagle por su conexión a la Antártida, durante 2013 y 2014 se incrementaron ejercicios con diverso grado de dificultad. Estos contaron con la participación de unidades navales y aeronavales con asiento en la ciudad de Ushuaia y Puerto Williams, y más de 200 efectivos de ambos países.

En el verano 2014-2015 se concretó la decimoséptima versión de la PANC, el operativo binacional entre las Fuerzas Armadas de la Argentina y las de Chile que tienen por misión salvaguardar la vida humana en el mar y combatir la contaminación para prevenir emergencias en aguas antárticas. Con el incremento del turismo antártico en la zona de la Península Antártica, su misión se vuelve imprescindible. ${ }^{16}$

La cooperación antártica argentino-chilena es una de las que posee mayor potencial estratégico por lo que, ya en el espacio regional de las Reuniones de Administradores de Programas Antárticos Latinoamericanos (RAPAL) como en las acciones de carácter bilateral propiamente dicho, deben continuar profundizándose y aprovechando el capital científico y político acumulado por ambos países en tantos años de quehacer antártico sostenido.

\section{Conclusiones}

El ascenso positivo, la continuidad y el reforzamiento de la relación bilateral argentinochilena —que tuvo como primer paso el Tratado de Paz y Amistad del año 1984 y fue adquiriendo avances cualitativamente relevantes desde 1991, ya con gobiernos democráticos en ambas partes- puede explicarse en la combinación de una variedad de factores, pero otorgando a la variable política la condición de básica y definitoria.

Argentina y Chile en la década de los años noventa se propusieron incrementar sus relaciones, acordando sobre la institucionalidad y ciertos principios republicanos básicos

\footnotetext{
${ }^{16}$ Durante la operación 2014/2014 se navegaron 14.743 millas náuticas en un total de 149 días, se visitaron 45 bases de 9 nacionalidades, se dio apoyo e identificó a 123 buques. Asimismo, se llevó a cabo el salvamento y salvataje del yate polaco "Polonus" y se concretó una evacuación médica desde el yate Australiano "Icebierd" (Prensa Antártica, 2015).
} 
y decidieron la orientación de sus futuros vínculos a partir de la construcción de una relación en clave de mutua confianza. A partir de entonces, y siguiendo lo que podría caracterizarse como una "política de estado" en el sentido que se proyecta en el tiempo con una línea de continuidad en diferentes gobiernos —en uno y otro país—, se han ido forjando espacios, canales e instituciones que estimulan la cooperación en múltiples niveles de gobierno. Si se pondera la multiplicidad de escenarios de vinculación desarrollados en estos 25 años de "nueva relación" y la continuidad y voluntad de profundización expresada, por ejemplo en el Tratado de Maipú (2009), es posible sostener que Argentina y Chile, en tanto relación vecinal, exhiben rasgos distintivos, casi únicos en el escenario de las relaciones sudamericanas y, dentro del amplio campo de las relaciones bilaterales entre ambos países, el entrelazamiento a escala subnacional, es uno de los que marca la diferencia; podríamos afirmar que dicho Tratado es una interesante pieza políticojurídica que muestra conceptos aggiornados e instituciones dinamizadoras de una relación bilateral entre dos estados.

La conformación de instancias del tipo de los Comités de Integración, Comisiones mixtas, relaciones interparlamentarias y diversos foros de intercambio provincial y municipal, favorecieron la consulta y coordinación, contribuyendo a diseñar una "interdependencia ordenada y fructífera".

Nos encontramos claramente frente a una sumatoria de propósitos y acciones donde se complementan la política exterior tradicional —esto es, la que asumen los Ejecutivos y los ministerios de relaciones exteriores- con la variedad y creatividad de las propuestas y realizaciones procedentes de ámbitos subnacionales.

Precisamente la acción subnacional, en todas sus manifestaciones, le ha sumado a esta relación bilateral una dinámica sin precedentes, favoreciendo el diálogo público-privado y ha estimulado a las propias cancillerías a tomar contacto directo con requerimientos provinciales o cuestiones más locales. En cuanto al análisis de la relación argentino-chilena anclada en la variable política, no nos queda duda de que a los actores subnacionales, subestatales y gobiernos no centrales les correspondió una tarea de construcción muy relevante, a partir de la vuelta a la democracia en los dos países. Favorecieron el diálogo, ayudaron a cimentar lo simbólico y lo material —ideas e intereses- en la relación de unos con otros más allá de las fronteras.

Se trabajó en diferentes instancias y con diferente grado de institucionalidad poniendo en foco la colaboración, negociación y concertación en base a intereses, en gran medida, compartidos y complementarios. De ese modo se contribuyó a la gestación de una "interdependencia ordenada", haciendo que la política exterior que ha sido siempre cerrada y centrada, vaya incorporando ideas, percepciones y reconociendo intereses y necesidades de los actores que desarrollan su vida diaria muchas veces en territorios muy alejados de las "capitales".

Los tres ejemplos seleccionados en este trabajo son una muestra - cada uno con sus características singulares - del modo en que evoluciona el concepto de "frontera" en la relación argentino-chilena, donde se combinan decisiones que involucran a los Ejecutivos, a algunas áreas de la administración del Estado y a los actores subnacionales representados por gobiernos no centrales, universidades, etc. Los diseños que esas acciones van adquiriendo son el resultado de la confluencia y complementariedad entre los niveles involucrados. Por otra parte, la conformación de la Zicosur, como hemos visto, permite observar que en el caso de las relaciones entre Estados fronterizos, este abanico de actores, agentes gubernamentales, entidades políticas subestatales y locales pueden llegar a tener un rol determinante.

En la cuestión antártica, en tanto, prevalece la decisión de los Estados centrales de favorecer el trabajo cooperativo, el diseño de políticas compatibles y el estímulo de acciones conjuntas 
que comprometen a las respectivas armadas nacionales y a las instituciones científicas y logísticas del quehacer antártico. Dichas actividades conjuntas — donde se están dando pasos importantes que contribuyen al propio vínculo bilateral- también legitima a ambos actores en el marco del Tratado Antártico y la defensa medioambiental de la región.

En suma, la relación bilateral argentino-chilena de nuevo cuño, implementada desde la década de los noventa y anclada fuertemente en la variable política y la agenda democrática, es el resultado de la combinación de acciones gubernamentales que promueven el diálogo y la cooperación y se retroalimentan con las propuestas de carácter subnacional y de áreas funcionales específicas.

\section{Referencias}

ANR International. (15 de mayo de 2013). Conociendo las Redes Internacionales: CRISCOS [Mensaje de un blog]. Recuperado de https://anrinternacional.wordpress. com/2013/05/15/conociendo-las-redes-internacionales-criscos/

Aseguran que "la relación entre Argentina y Chile es de enorme dimensión". (29 de marzo de 2015). La Capital, p. 2.

Boisier, S. (2003). Globalización, geografía política y fronteras. Anales de Geografía de la Universidad Complutense, 23, 21-39.

Colacrai, M. (2010). Argentina-Chile. Las relaciones políticas y el crecimiento de un notable tejido de vínculos a escala nacional y subnacional. La política exterior de Cristina Fernández. Apreciaciones promediando su mandato (pp. 321-362). Rosario, Argentina: UNR Editora.

Diesbach de Rochefort, N. (2002). Frontera: ¿muro divisorio o tejido de relaciones? Estudios Fronterizos, 3(5), 9-42.

Hoy finaliza en unca el encuentro de referentes del Programa de Movilidad Estudiantil en la Red Criscos. (6 de agosto de 2007). Diarioc. Recuperado de http://www.diarioc.com.ar/educacion/id/94739

Medina, E. (2006). Aportaciones para una epistemología de los estudios sobre fronteras internacionales. Estudios Fronterizos, 17(13), 9-27.

Ohmae, K. (2008). El próximo escenario global. Desafíos y oportunidades en un mundo sin fronteras. México: Editorial Norma.

Pinochet de la Barra, O. (1999). Chile y Argentina en la Antártica: Algunas reflexiones (Documento de trabajo, núm. 34). Buenos Aires, Argentina: Consejo Argentino para las Relaciones Internacionales.

Prensa Antártica. (16 de abril de 2015). Tras aumento de turismo en la Antártica, armadas extenderán patrullaje durante 2015 [Mensaje en un blog]. Recuperado de https:// prensaantartica.wordpress.com/tag/cooperacion/

Rhi, J. L. y Conato, D. (2009). Cooperación transfronteriza e integración en América Latina. Roma, Italia: Centro Superior para el Procesamiento de la Información e Instituto Italo-Latino Americano.

Schmitter, P. (1989). Idealismo, integración, cambio de régimen en el Cono Sur. Revista Estudios Internacionales, XXII(85), 78-130.

Universidad Arturo Prat (UNAP). (s. f.). Universidades Criscos profundizan integración en UNAP Santiago. Recuperado de http://www.unap.cl/prontus_unap/site/artic/20141113/pags/20141113132318.html 
Wendt, A. (1992). Anarchy is what states make of it: the social construction of power politics. International Organization, 46(2), 391-425.

\section{Material legislativo}

Acuerdo entre la República de Chile y la República de Argentina para el establecimiento de un nuevo Reglamento para los Comités de Integración (2011).

Declaración Conjunta Argentino-Chilena (1947).

Declaración Presidencial Conjunta de Menem-Aylwin (1990).

Decreto 278 Promulga el Acuerdo con Argentina relativo al cambio de denominación de los Comités de Frontera, Biblioteca del Congreso Nacional de Chile (2006).

Tratado de Maipú de Integración y Cooperación entre la República Argentina y la República de Chile, firmado el 18 de noviembre de 2009. Recuperado de http://www1.hcdn. gov.ar/dependencias/dsecretaria/Periodo2009/PDF2009/TP2009/0086-S-09.pdf

Tratado de Paz y Amistad de 1984 firmado entre la República Argentina y la República de Chile en la Ciudad del Vaticano, el 29 de noviembre de 1984. Recuperado de http://www.bcn.cl/obtienearchivo?id=recursoslegales/10221.3/35109/1/Tratado_de_Paz_y_Amistad.PDF

\section{Miryam Colacrai}

Argentina. Doctora en Ciencias Sociales, Licenciada en Relaciones Internacionales. Investigadora Principal del Consejo Nacional de Investigaciones Científicas y Técnicas (Conicet, Argentina). Profesora Titular de Teoría de las Relaciones Internacionales en la Facultad de Ciencia Política y Relaciones de la Universidad Nacional de Rosario. Fundadora y coordinadora de la "Cátedra Chile" en dicha Institución. Directora de la Maestría en Integración y Cooperación Internacional de la UNR. Co-Directora del CERIR (Centro de Estudios en Relaciones Internacionales de Rosario) y Profesora de postgrado a nivel de Maestrías y Doctorados en la especialidad de Relaciones Internacionales. 